\title{
ANÁLISIS DE LA VARIEDAD QUICHUA SANTIAGUEÑO. ASPECTO LINGÜÍSTICO Y SOCIO HISTÓRICO
}

\author{
ANALYSIS OF THE QUICHUA VARIETY FROM SANTIAGO. LINGUISTIC \\ AND SOCIO-HISTORICAL ASPECT \\ (iD) Raúl Orlando Banegas ${ }^{1^{*}}$ \\ raulbanegas2@hotmail.com \\ ${ }^{1}$ Universidad Nacional de Santiago del Estero, Argentina
}

*Correspondencia: Raúl Orlando Banegas. Email: raulbanegas2@hotmail.com

Recibido: 15.08.21 | Aprobado: 08.09.21

\section{RESUMEN}

La evanescencia de las lenguas aborígenes se aceleró durante las últimas décadas del siglo pasado, estimándose que en la presente centuria desaparecerán más de la mitad de los 4000 idiomas existentes. Lamentablemente no existen reportes favorables acerca de experiencias de recuperación y revitalización lingüística, por lo que se deben tomar medidas urgentes. En algunos territorios estos idiomas se ven relegados a la condición de dialectos y están desvalorizadas en relación con el lenguaje nacional, lo cual las condena a una muerte segura. El objetivo de este trabajo consiste en explorar sobre la variedad dialectal del Quichua Santiagueño haciendo hincapié en el aspecto lingüístico y socio histórico.

Palabras clave: Quichua en Santiago del estero, bilingüismo, políticas lingüísticas

\section{ABSTRACT}

The evanescence of aboriginal languages accelerated during the last decades of the last century, estimating that in the present century more than half of the 4,000 languages will disappear. Unfortunately, there are no favorable reports about language recovery and revitalization experiences, so urgent measures must be taken. In some territories, these languages are relegated to the status of dialects and are devalued in relation to the national language, which means death to certain death. The aim of this essay is to explore the Quichua Santiagueño variety and linguistic policies

Keywords: Quichua in Santiago del estero, bilingualism, linguisticpolicies

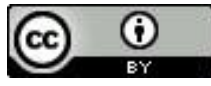




\section{EL QUICHUA SANTIAGUEÑO}

En la actualidad, alrededor de 300 lenguas aborígenes que corren riesgo de desaparecer en Latinoamérica; las políticas lingüísticas en nuestros países (en algunos casos inexistentes) deberían resguardar este patrimonio cultural e intangible. Estos idiomas se encuentran desprotegidos y vemos que década tras década se extinguen inevitablemente.

En la región Latinoamericana, la lengua aborigen que cuenta con un número mayor de hablantes es el quechua, con aproximadamente 10.000.000, los cuales se encuentran geográficamente distribuidos en países como Ecuador, Perú, Bolivia y Argentina. En este último país, es el segundo idioma más hablado por debajo del castellano, fue tan importante la presencia del quechua (dentro de los mencionados) que su Acta de Declaración de la Independencia fue redactada en quechua y en español.

En Santiago del Estero, provincia ubicada al noroeste de la República Argentina, existe una subvariedad del quechua, denominada quichua santiagueño hablado por aproximadamente 160.000 personas y se extiende por alrededor de 16 departamentos Atamisqui, Avellaneda, Figueroa, Loreto, Mitre, Quebrachos, Robles, San Martin, Sarmiento, Silípica y Salavina, y parte de los departamentos Capital, Juan Felipe Ibarra, Moreno y Taboada a lo largo del río Salado. También en Buenos Aires por alrededor de 450.000 migrantes que provienen de Perú. La relación etnia-quichua no es consustancial por el aglomerado étnico aborigen, afroamericano, europeo y árabe, en que se transformó el sector bilingüe desde el siglo XIX.

El quichua de Santiago del Estero, según lo señalan Generoso y Banegas (2020) es una amalgama de varios dialectos quechuas como el sureño y el norteño y a su vez, producto de varias corrientes migratorias en la provincia, con una vehemente relación con los habitantes de la Mesopotamia santiagueña (prehispánicas y el incanato). Los y las quichuistas no son un grupo lingǘstico uniforme, sino que existe una diversidad de hablantes con distintas variantes como por ejemplo el dominio, la valoración y el uso.

Esta variedad del quechua hablado en el norte argentino presenta ciertas características fonológicas similares al grupo IIB (carece de distinción entre consonantes posvelares y velares) y al subgrupo IIA (conserva la distinción entre posvelares y velares). Otra característica importante de destacar es que, el QS presenta cierto paralelismo con el quechua IIC en cuanto a la morfología verbal y el léxico.

Existen varias posturas acerca de la introducción de la lengua en la provincia; entre las que destacaremos las más importantes. En el año 1861 se insertó la primera polémica cuando Juan María Gutiérrez público un artículo en la revista tucumana "El orden" titulado "La quichua de Santiago del Estero" donde sostiene la llegada del idioma con los españoles; por su parte Vicente Quesada toma esto y responde que su entrada fue el resultado de la dominación inca y por ende anterior a la llegada de los conquistadores europeos, en su publicación "Apuntes sobre el origen de la lengua quichua en Santiago del Estero" del año 1863. 
Autores como Lizondo Borda (1928) postulaban que el origen de esta lengua era pos hispánica, puesto que ni siquiera el tránsito de, los guerreros del imperio incaico llegaron a suelo santiagueño. Por su parte Ledesma Medina (1946) sostiene que la comarca de Santiago del Estero se mantuvo ajena a los dominios de los hijos del sol; posteriormente Figueroa (1949) en "pueblos de indios de Santiago del Estero" plantea que "los tonocotés ya hablaban en su mayor parte el quichua en estas regiones, en tiempo de la conquista española. Mientras que para Gargaro (1943) la región del noroeste argentino fue una zona muy influenciada por la expansión del territorio inca, sobre todo en lo que respecta a la conquista del Collasuyu en tiempos del inca Tupac Yupanqui.

Gargaro (1953) sostuvo que el quichua era el resultado del dominio cultural de los incas mucho antes de la presencia española, por medio de los mitimaes encargados de la enseñanza del idioma en la región bajo la dirección del incanato. Un año más tarde Santucho (1954) adhiere a la hipótesis pre hispánica en "el indio en la provincia de Santiago del Estero", descartando toda posibilidad de que el español haya diseminado la cultura del inca conjuntamente con la lengua quichua; este autor se sustentaba en mitos y leyendas y también en las denominaciones y vocabularios.

Tres años más tarde Bravo (1957), sostenía que el quichua habría llegado de mano de los conquistadores en 1543 con Diego de Rojas, en paralelo con el castellano, al actual territorio de Soconcho. Mientras que la expansión de la lengua se logró gracias a los religiosos y a la administración española. Christensen (1970) sostiene que la comunidad aborigen de los juries (en la Mesopotamia de los ríos Dulce y Salado) era quichuahablante y sedentaria, pero que provino del Cuzco: al momento de la llegada de los conquistadores, daba los primeros pasos por el camino de la civilización. Con un enfoque más sistémico Stark (1985) afirma que hay evidencias tanto arqueológicas como etnohistóricas que dan cuenta de la presencia del inca en suelo santiagueño. También hace referencia a la presencia de metales incaicos encontrados en 1940.

Lorandi (1980) plantea la posibilidad de que la presencia del quichua en Santiago se debió a la introducción por parte de los mitimaes quienes regresaban a sus hogares, tras ser trasladados a los valles del NOA llevando consigo la técnica de la alfarería. Y que quizás los incas, sin efectivizar su comparecencia en la llanura santiagueña entablaron algún tipo de convenio para el cuidado de la frontera oriental, rebatiendo la postura de Bravo a cerca de la inmersión española. Por lo tanto, la situación de nuestra provincia muestra cierto paralelismo con otras áreas donde el quechua fue introducido en forma tardía.

Debido al uso de la lengua quichua en la catequización y al proceso de mestizaje que se inició con la llegada de los primeros pobladores españoles, este idioma (con su particularidad regional) fue adoptado como lengua vehicular y de uso cotidiano por la población española, criolla y mestiza (Generoso y Banegas, 2020). Esto sirvió para disociar la lengua de su pasado indígena y estimar que la lengua se encontraba en proceso de retracción. Aproximadamente 160.000 de estos hablantes son bilingües quichuacastellano y no quichua hablantes en sentido estricto, al no encontrarse casos de hablantes monolingües de quichua ni aun en personas de avanzada edad. 
Es importante recalcar que, en 1770, el rey Carlos III prohibió el uso de la lengua quichua en el ámbito oficial. Y es que de esta manera se la fue recluyendo hasta solo ser hablada en el ámbito familiar -en notable diglosia - dejando la trasmisión oral de generación en generación, a pesar de la marginalidad a la que se vio expuesta. Como resultado de esta realidad sociolingüística, se generó una nueva variedad del castellano poblado por marcas del quichua mediante transferencias de orden sintáctico, fonológico, léxico y morfológico. En Santiago del Estero existen habitantes que se definen bilingües. Siguiendo a Siguan (2001) un bilingüe es aquel individuo capaz de utilizar dos lenguas alternativamente, pasando de un idioma a otro.

La variedad del quechua a la que nos referimos en este trabajo, se usa solo en el ámbito doméstico-familiar. El traspaso del idioma fue mediante la oralidad, es decir de padres a hijos en el hogar, ya que la gran mayoría de los hablantes desconocía su escritura. No obstante, la transmisión es cada vez menor, al tratarse de una lengua invisibilizada y discriminada. El castellano al gozar de un status de jerarquía, las personas mayores deciden cortar esa transferencia lingüística, considerando que no es útil aprender una lengua que no se usa en el ámbito oficial ni tampoco goza de un prestigio, y como consecuencia sus descendientes serán objeto de exclusión.

En nuestra sociedad es notoria la influencia del quichua en el habla cotidiana. Aquí, el contacto lingüístico con el castellano generó una nueva variedad lingüística, Grosso (2008) afirma que el sociolecto rural español en roce con el QS es la castilla, visibilizado como el habla netamente santiagueña frente al discurso nacional. Actualmente la investigadora y profesora Lelia Albarracín de Alderetes saco a la luz un alfabeto que aún se sigue perfeccionando, y todavía no es utilizado en su totalidad por los hablantes. Asi mismo, en diferentes puntos del país, ciudades importantes como Buenos Aires, es posible encontrar otra variedad quechua, el dialecto cuzqueño-boliviano hablado en su mayoría por inmigrantes. Sólo para la Ciudad de Buenos Aires se señalan estimaciones de alrededor de medio millón de quechuahablantes (Burke.1995).

Según la escala propuesta por Fishman (1991) podríamos anticipar que la lengua quichua (santiagueño) se encuentra en transición entre los niveles 5/6 y $6 / 7$ respectivamente, con el riesgo que ello implica. Siguiendo a Nardi (1962) podemos afirmar que, aunque los estudios de Fishman están basados en minorías sociolingüísticas estadounidenses, su escala tiene cierto grado de generalidad y aporta información relevante.

\section{POLÍTICAS EDUCATIVAS COMO POLÍTICAS LINGÜÍSTICAS}

Una política lingüística representa el conjunto de elecciones conscientes que atañen a las relaciones entre lenguas y vida social. En consecuencia, su función es la determinación de las grandes opciones en materia de relaciones entre la lengua y la sociedad; su puesta en práctica se da por medio de la planificación lingüística (Arnoux y Bein, 2015). El comportamiento lingüístico es el resultado de la interacción entre las medidas que el Estado adopta y ha adoptado a lo largo de la historia, en paralelo con las corrientes inmigratorias. A partir del período de 1880-1930 se dio un proceso que se caracterizó por una tendencia al monolingüismo, resultado de una política estatal referida 
a la integración del inmigrante, acompañada por una política lingüística propulsora del español como "lengua nacional", asociado a "lengua del Estado".

Durante este lapso de tiempo las decisiones lingüísticas estatales comenzaron a centrarse en la educación, otorgándole una función homogeneizadora. En términos simbólicos, la instauración de una lengua oficial intenta contribuir a la unidad nacional; frente a ello y dado el carácter coactivo de la medida, se produce un conflicto entre las lenguas de inmigración y la lengua propuesta por el Estado. Frente a la hostilidad resultante, el Estado activa regulaciones e impone políticas lingüísticas produciendo un proceso de adaptación inconclusa de la población migrante y los pueblos originarios, cuestión que permanece hasta el presente (Arnoux y Bein, 1997). Es posible afirmar que con el arribo de la masiva inmigración producida entre 1880 y 1930, se ve modificada la relación entre la Lengua y el proyecto de Nación. La función simbólica de la lengua española como factor de identidad colectiva y hegemónica se ve reforzada por la masa inmigrante.

El ámbito privilegiado de la acción y aplicación de estas políticas es la educación primaria, que cumplirá con la función de erradicar todo vestigio de rasgos idiosincrásicos y de los valores, cultura y lengua de los inmigrantes, para lograr el ideal de un estado monocultural y monolingüe e imponer el idioma oficial a poblaciones con lenguas vernáculas diferentes.

Anteriormente señalamos que la educación se convertiría en instrumento principal del proyecto de homogenización del idioma y la cultura, también que existió una estrecha relación entre lengua e inmigración en el período comprendido entre los años 1880 y 1930, y que la masa inmigratoria obligó al naciente Estado Nación Argentino a replantear su política lingüística haciendo de la educación un instrumento para su estrategia.

Di Tulio (2010) propone tres etapas en el periodo señalado. La primera etapa que va de 1880 a 1907, se caracteriza por el optimismo pedagógico y por el espíritu pragmático, se extiende la educación a las colonias de inmigrantes para integrar a los extranjeros. En cuanto a las políticas lingüísticas de este periodo, podemos señalar el intento de imponer el uso obligatorio del español para impartir la enseñanza en las escuelas nacionales y particulares, el Poder Ejecutivo lo vetó por considerarlo una violación a la libertad de enseñanza y un acto de hostilidad hacia los inmigrantes. Señalamos otro hecho llamativo; la enseñanza de la lengua debía estar a cargo de un maestro cuya lengua materna fuera el español.

En el segundo periodo, comprendido entre 1908 y 1912, se produce el llamado a constituir una "educación patriótica" que nace en reacción a un inmigrante que comienza a ser juzgado como elemento disolvente de la nacionalidad. La política educativa será destinada a neutralizar el peligro; se pretende imbuir a través de un adoctrinamiento sostenido de actitudes y sentimientos nacionalistas a la población estudiantil; la instrucción queda subordinada a un proyecto en el que se antepone la función de adoctrinamiento ideológico.

Finalmente, entre 1912 y 1930, si bien se mantiene la orientación nacionalista, se recuperan los contenidos específicos, no evaluados ya por su valor pragmático o 
estrictamente ideológico sino por la eficacia pedagógica que se les asigna, mientras se van abriendo camino innovaciones curriculares y metodológicas. Hacia 1920, cuando la tendencia patriótica se cristaliza, la cuestión inmigratoria pasa a segundo plano, subordinada a la necesidad de modernizar la educación.

A fines del siglo XX, en el año 1994, se lleva a cabo la Reforma de la Constitución Nacional, que en su artículo 75 inc.17 señala tanto el reconocimiento de la preexistencia étnica y cultural de los pueblos originarios argentinos como el respeto a su identidad y el derecho a una educación bilingüe e intercultural, aunque es importante aclarar que no se establece una lengua oficial. Asimismo, se incluye el derecho gratuito a traductor o intérprete de cualquier inculpado que no hable español (Pacto de San José de Costa Rica, 1969; Ley argentina 23.054 de 1984). Con esta inclusión, se inscribe el derecho a la lengua propia como uno de los derechos humanos irrenunciables y garantizados por el Estado nacional.

En la Ley Nacional de Educación vigente, aprobada el 14 de diciembre de 2006, el español se representa por defecto, en la medida en que se sobreentiende como lengua de hecho, y la referencia a la lengua sólo se presenta en relación con los pueblos originarios: "Asegurar a los pueblos indígenas el respeto a su lengua y a su identidad cultural y al definir EIB, garantizar el derecho constitucional de los pueblos indígenas a recibir una educación que contribuya a preservar y fortalecer sus pautas culturales, su lengua, su cosmovisión e identidad étnica; a desempeñarse activamente en un mundo multicultural y a mejorar su calidad de vida".

En nuestra provincia existieron distintos documentos que proponían la enseñanza del quichua, no obstante, en la práctica no se atendía al bilingüismo desde lo curricular; el uso de esta lengua quedaba a criterio del personal docente. En atención a la diversidad existente en nuestro territorio, se produjeron una serie de documentos que pretendían dar un marco legal a la enseñanza del quichua.

El Decreto Serie "E" No 4306 de 1983 que establece que "la Secretaría de Estado de Educación y Cultura estimulará el estudio y práctica del habla quichua a través de establecimientos educacionales de su dependencia". El mismo documento sugiere la celebración de convenios y convocar a la colaboración de personas y entidades que quieran sumarse. Tres años después, en el año 1986, se declara "de interés oficial la preservación, difusión, estímulo, estudio, práctica de la lengua quichua dentro y fuera de la provincia; estimular el estudio del habla, especialmente en las regiones donde es corriente su uso"; en otro fragmento propone "dar apoyo a todos los establecimientos educacionales de la provincia en lo referente a la elaboración de los planes concretos para el estudio y práctica del a lengua".

La Resolución No 1279/88 del Consejo General de Educación de la Provincia reza que "se aplica a partir del presente período lectivo, la enseñanza de la Lengua Quichua" esto se proponía para distintos establecimientos de algunas localidades de la Provincia, como Loreto, Bandera Bajada y Brea Pozo, para todas estas escuelas se creaba un cargo de Maestro Especial de Enseñanza Quichua- Castellano. 
En 1995, por disposición de la Intervención Federal, se promulgo la ley 6186 que promovía una reestructuración del plantel docente, situación que produce el cese del cargo de maestro de quichua de la escuela de Brea Pozo. En 1998 se pierde el cargo de Loreto, por traslado del docente; no se designó un reemplazante. En esta década, en la Universidad Nacional de Santiago del Estero se impartían cursos de Lingüística Regional Quichua- Castellano, dictados por Domingo Bravo y reconocidos por la Junta de Calificaciones y Clasificaciones de la Provincia de Santiago del Estero.

En 2007 se promulgó la Ley Provincial No 6876/2007 que en su artículo 62º establece:

"La Educación Intercultural es la modalidad que tiene como finalidad impulsar una perspectiva pedagógica intercultural en articulación con la Educación común, complementándola, enriqueciéndola, resaltando y destacando aquellos derechos, contenidos y prácticas que distinguen los procesos interculturales, las diferentes situaciones sociales y repertorios culturales, así como las relaciones que se establecen entre ellos, tanto temporal como permanentemente, propiciando el respeto y reconocimiento de tales diferencias".

El área de EIB (del ministerio provincial de educación) organizo desde 2007 y durante tres años consecutivos varios talleres que estaban coorganizados junto con los representantes aborígenes, posteriormente en 2008 creo un encuentro provincial con docentes, pueblos aborígenes y público interesado en la temática. En una entrevista realizada a su director, Rene Galván, nos relató que por falta de recursos y presupuesto no se realizan actividades, proyectos y programas relacionados a la EIB, a su vez el material didáctico confeccionado es modesto.

En 2010 el gobierno provincial anuncio, la creación de 12 cargos primarios para la enseñanza de la lengua quichua en escuelas de zonas consideradas bilingües, pero estos nunca se hicieron efectivos. Suponemos que el sector estatal no encuentra aún las perspectivas adecuadas para la gestión del bilingüismo, tampoco tienen en cuenta la función de la lengua materna para el desarrollo cognoscitivo y afectivo de los niños quichuahablantes, conjeturamos que por ello el castellano se convierte en la única lengua de instrucción.

Por su parte la Universidad Nacional de Santiago del Estero (UNSE) inicio dos procesos institucionales con un horizonte esperanzador hacia la lengua, el primero se trata de una "Diplomatura en Lingüística Quichua", con duración de un año y medio, y está destinada a docentes y público en general; hasta el año 2015 contaba con 200 egresados. El segundo se trata de una "Tecnicatura Superior en Educación Intercultural Bilingüe con mención en Lengua Quichua” esta carrera cuenta con 29 cátedras y tiene una duración de tres años, lanzada oficialmente en agosto de 2012, posee 16 egresados hasta diciembre de 2019.

Esta carrera tiene por objetivo "formar técnicos capaces de asesorar a instituciones (de carácter público y privadas) y organizaciones sociales en el diseño, ejecución y evaluación de programas y proyectos de educación intercultural bilingüe”. 


\section{CONCLUSIÓN}

En Argentina, la provincia de Santiago del Estero es la que cuenta con la mayor cantidad de quichuahablantes, personas portadoras de una lengua minoritaria que padece un alto grado de invisibilización y discriminación lingüística. Estos habitantes se encuentran ubicados en el interior provincial, pero a menudo optan por migrar hacia la Capital del país en busca de mejores condiciones de vida, ya que la región del Noroeste en la que se emplaza es una de las más pobres, se registran, según informes nacionales, altas tasas de analfabetismo y desempleo.

Estos factores terminan produciendo un desarraigo (o sea una pérdida de las raíces sociales y familiares sufriendo la identidad personal un extrañamiento) en los pobladores bilingües (quichua-castellano) lo que conlleva a la paulatina desaparición de la lengua ancestral.

La Tecnicatura en EIB con mención en Lengua quichua continúa formando profesionales año tras año desde su creación. Desde mi rol de tutor de alumnos ingresantes en la UNSE de la antes mencionada carrera, junto a estudiantes y técnicos llevamos a cabo actividades y proyectos de extensión universitaria como, por ejemplo: "La quichua en mi escuela", que consistió en brindar un taller de tipo expositivo en donde no solo se abordó lo teórico sino también algunas situaciones empíricas relacionadas al marco conceptual (EIB, Bilingüismo, Políticas Lingüísticas, Quichua) que se presenta. Se usaron recursos didácticos como diapositivas, películas e imágenes. Los objetivos planteados en torno este proyecto fueron:

1. Difundir los distintos aspectos lingüísticos relacionados a la quichua.

2. Exponer el contexto social e histórico de su aparición y desarrollo en nuestro territorio.

3. Concientizar acerca de la importancia de una convivencia de las distintas culturas en el seno de toda sociedad.

Además, por segundo año consecutivo realizamos una Jornada en conmemoración del Día Internacional de la Lengua Materna, en la primera edición se proyectó un documental titulado "Salavinamantatukuypaq" y posteriormente se realizó un debate entre los asistentes. En el presente año efectuamos un conversatorio intercultural, con ponencias de dos ensayos y contando con el acompañamiento de la FHCSyS- UNSE.

En el año 2018 y 2019 ejecutamos un Ciclo de Cine con temática Intercultural, abierta a toda la comunidad universitaria con el objetivo de concientizaracerca de los problemas que existen con las comunidades aborígenes en Latinoamérica y la importancia de la revitalización lingüística. Dicho evento recibió la declaración de interés provincial cultural, educativo y social por la Cámara de Diputados de Santiago del Estero. En el presente año ante el actual panorama de pandemia confeccionamos guías con medidas de prevención sobre covid-19, dengue y violencia de género, para ser difundido a las comunidades quichuahablantes de la provincia.

\section{REFERENCIAS BIBLIOGRÁFICAS}

Albarracin L., Tebes M. y Alderetes J. (2002) Introducción al Quichua Santiagueño por Ricardo Nardi. Editorial Dunken, Buenos Aires. 
Albarracín, L. (2016): La Quichua. Gramática, ejercicios y Diccionario QuichuaCastellano. Volumen 3. Universidad Nacional de Tucumán: Editorial Dunken.

Adelaar, W. (1984). Grammatical vowel lenght and the classification of Quechua dialects. International Journal of American Linguistics. Vol. 50, No. 1. The University of Chicago Press, pp. 25-47

Adelaar, W. (1995). Raiceslinguisticas del quichua de Santiago del Estero. Actas de las Segundas Jornadas de Lingüística Aborigen, UBA, Buenos Aires, pp. 25-50.

Borda, L. (1928) "El quichua de Santiago". En La Brasa periódico mensual de Letras y Artes. Año II no 4 .

Burke P. (1985) "IndigenousPeople in Argentina", disponible en Internet: http://www.soc.uu.se/mapuche/indgen/Indarg01.html.

Bravo, D. (1992) El quichua santiagueño es el quichua argentino, Santiago del Estero: Edición del autor.

Bravo, D. (1993). El quichua santiagueño es el quichua argentino. Actas de las Primeras Jornadas de Lingüística Aborigen. Buenos Aires, pp. 35-46.

Censabella, M. (1995). Las lenguas indígenas en la Argentina: una mirada actual. Buenos Aires: Eudeba.

Figueroa, A. (1943). "Los antiguos pueblos de indios de Santiago del Estero". Revista del archivo de Santiago del Estero n ${ }^{\circ} 1,2$ y 3.

Gargaro, A. (1943) “Diego de Rojas y la primera entrada española al Tucumán”. En: Revista de la junta de Estudios Históricos de Santiago del Estero. Año 1. No 1. Tucuman. La Raza

Fishman, J. (1991) Reversing Language Shift. Clevedon, UK: Multilingual Matters.

Ledesma Medina, L. (1946). La lengua quichua y su difusión en el territorio del antiguo Virreinato del Perú. En: Revista de la Junta de Estudios Historicos de Santiago del Estero, Año 4, Nos. 11-13. Tucumán. La Raza

Lorandi, A. (1980) “La frontera oriental DelTawantisuyu: el Umasuyu y el Tucuman", en Relaciones de la Sociedad Argentina de Antropología 14.

Siguán, M. (2001): Bilingüismo y Lenguas en contacto: Alianza Ensayo

Stark, L. (1985) History of the Quichua of Santiago del Estero. En: H.M. Klein y L.R. Stark (eds.) South American Indian Languages: Retrospect and Prospect (pp. 732752). Texas. Universidad de Texas. 
PURIQ Vol. 3, Núm. 4. 2021 |ISSN 2664-4029|E-ISSN 2707-3602

Universidad Nacional Autónoma de Huanta

ANEXO

Departamentos provinciales en donde se habla Quichua

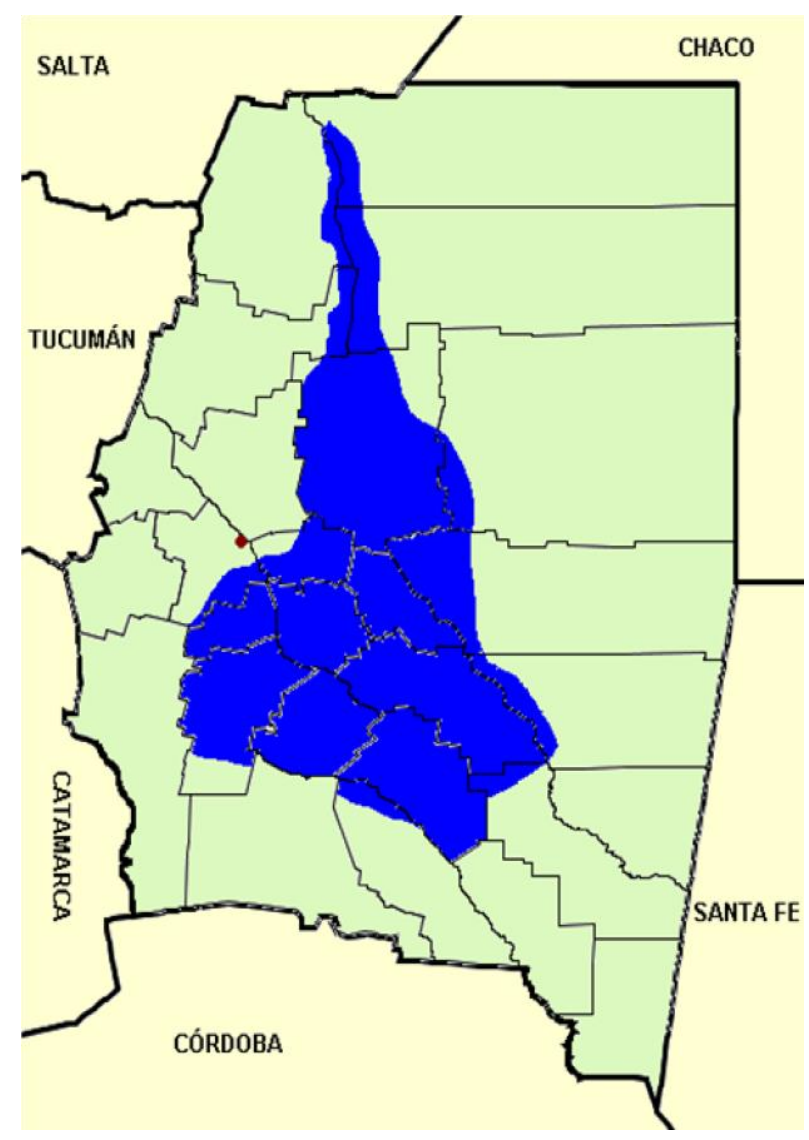

Proyecto de Extensión Universitaria 2019

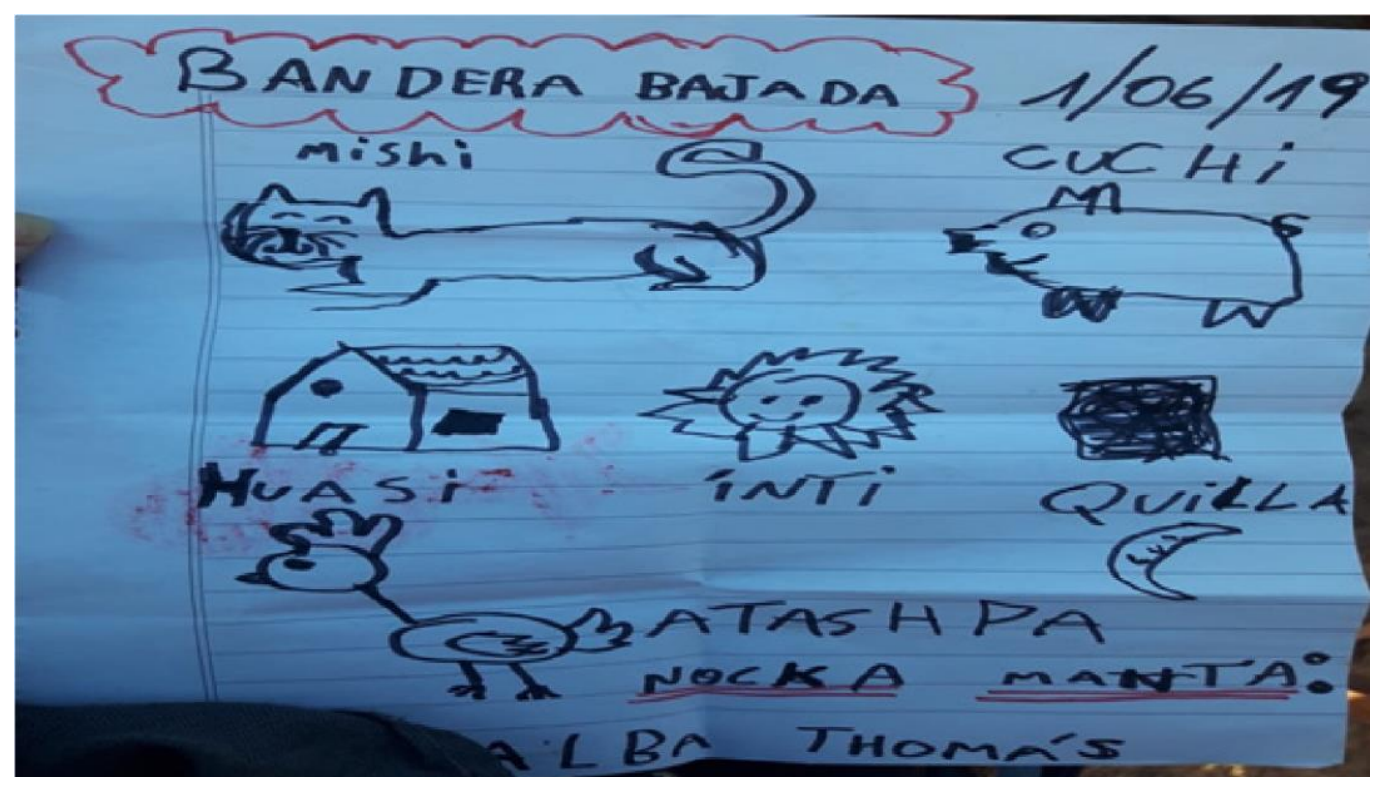

PURIQ

609 